\title{
Ballistic impact on concrete slabs: An experimental and numerical study
}

\author{
Martin Kristoffersen ${ }^{1,2}$, Oda Lunde Toreskås ${ }^{3}$, Sumita Dey ${ }^{3}$, and Tore Børvik ${ }^{1,2,3, *}$ \\ ${ }^{1}$ Structural Impact Laboratory (SIMLab), Department of Structural Engineering, NTNU - Norwegian \\ University of Science and Technology, Trondheim, Norway \\ ${ }^{2}$ Centre for Advanced Structural Analysis (CASA), NTNU, Trondheim, Norway \\ ${ }^{3}$ Research and Development Department, Norwegian Defence Estates Agency, Oslo, Norway
}

\begin{abstract}
The ballistic perforation resistance of $50 \mathrm{~mm}$ thick concrete slabs impacted by $20 \mathrm{~mm}$ diameter ogive-nose steel projectiles is investigated experimentally and numerically. Three commercially produced concretes with nominal unconfined compressive strengths of 35,75 and $110 \mathrm{MPa}$ were used to cast material test specimens and slabs. After curing, ballistic impact tests were carried out to determine the ballistic limit curve and velocity for each slab quality. Material tests instrumented with digital image correlation (DIC) were conducted along the ballistic impact tests. DIC measurements were used to establish engineering stress-strain curves for calibration of a modified version of the Holmquist-Johnson-Cook concrete model. Finite element simulations of the impact tests gave good conservative predictions.
\end{abstract}

\section{Introduction}

Concrete is the most widely used construction material in the world and is often used in protective structures exposed to extreme loads such as explosions or ballistic impact. Studies on ballistic impact typically concern either deep penetration or perforation. For the former, where a high level of confinement is present, the compressive strength of the concrete has been shown to be the primary variable [1]. For the latter, the process is more complex and the concrete experiences multiple damage and failure mechanisms, including spalling, tunnelling, and scabbing [2]. The various damage and failure mechanisms are discussed in [3]. Experiments on reinforced concrete slabs with unconfined compressive strengths $f_{\text {cyl }}$ of 48 and $140 \mathrm{MPa}$ have for instance shown that tripling $f_{\text {cyl }}$ increased the ballistic limit by less than $20 \%$ [4]. Slabs with strengths ranging from $f_{\text {cyl }}=25 \mathrm{MPa}$ to $200 \mathrm{MPa}$ produced similar results [5] - a roughly linear increase in ballistic limit of $50 \%$ when increasing $f_{\text {cyl }}$ by a factor of 8 . While $f_{\text {cyl }}$ is important in many respects, the tensile strength seems to be a more adequate material parameter for the perforation resistance of thin concrete slabs [6].

Analytical and/or empirical approaches have been used extensively for modelling problems of this kind, but with the rapid increase in computational power, more and more studies are now numerical (see e.g. Ref. [7]). Several concrete models are available [8], each with their strengths and weaknesses. A model may be easy to calibrate but lack the

\footnotetext{
* Corresponding author: tore.borvik@ntnu.no
} 
sophistication to capture all relevant phenomena accurately (or vice versa). Polanco-Loria et al. [3] proposed some modifications to the Holmquist-Johnson-Cook (HJC) model [9] as an engineering compromise. The modified HJC (or MHJC) model was only validated against some data from the literature [3]. This study aims to reveal the accuracy of the MHJC model in predicting the ballistic perforation resistance of concrete slabs impacted by ogive-nose steel projectiles using standard material tests to calibrate the constitutive relation.

\section{Material tests}

Cylinders with diameter $100 \mathrm{~mm}$ and height $200 \mathrm{~mm}$ and $100 \mathrm{~mm}$ cubes were used. Three different concretes were tested, dubbed C35, C75 and C110, where the number refers to nominal unconfined compressive strength in MPa. All specimens were painted with a speckled pattern (see Fig. 1(a)) for use with DIC. The engineering strain $e$ was estimated by tracking the relative vertical displacement $\Delta \ell$ of five opposing subset pairs throughout the test and dividing by the initial distance $\ell_{0}$ between the subsets as illustrated in Fig. 1(a). The engineering stress was obtained by dividing the force (synchronised with the images) by the initial loaded area. All resulting curves are plotted in Fig. 1(b)-(d), where each curve is the average of three tests. Table 1 summarises the results, where $\rho_{0}$ is the density, $f_{\text {cyl }}$ the cylinder compressive strength, $f_{\text {cube }}$ the cube compressive strength, and $f_{\mathrm{t}}$ the tensile splitting strength.
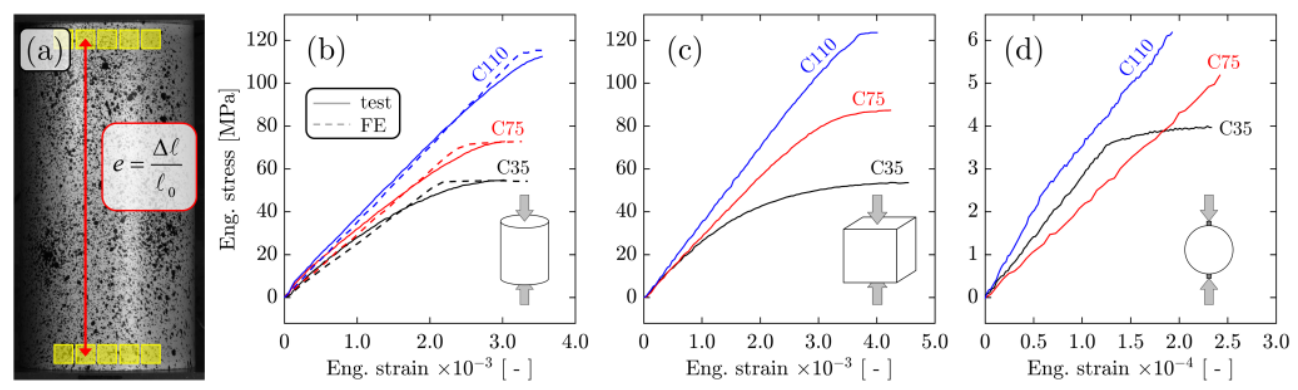

Fig. 1. Material test procedure where (a) shows the DIC setup, and the resulting engineering stressstrain curves for (b) cylinder compression, (c) cube compression and (d) tensile splitting tests.

Table 1. Results from material tests, ballistic impact tests, and ballistic impact simulations.

\begin{tabular}{|c|c|c|c|c|c|c|c|c|c|c|}
\hline & \multicolumn{4}{|c|}{ Material tests } & \multicolumn{3}{|c|}{ Impact tests } & \multicolumn{3}{|c|}{ Impact simulations } \\
\hline & $\begin{array}{c}\rho_{0} \\
{\left[\mathrm{~kg} / \mathrm{m}^{3}\right]}\end{array}$ & $\begin{array}{c}f_{\text {cyl }} \\
{[\mathrm{MPa}]}\end{array}$ & $\begin{array}{c}f_{\text {cube }} \\
{[\mathrm{MPa}]}\end{array}$ & $\begin{array}{c}f_{\mathrm{t}} \\
{[\mathrm{MPa}]}\end{array}$ & $\begin{array}{l}a \\
- \\
\end{array}$ & $\begin{array}{l}p \\
- \\
\end{array}$ & $\begin{array}{c}\nu \mathrm{bl} \\
{[\mathrm{m} / \mathrm{s}]}\end{array}$ & $\begin{array}{l}a \\
- \\
\end{array}$ & $\begin{array}{l}p \\
- \\
\end{array}$ & $\left.\begin{array}{c}v_{\mathrm{bl}} \\
{[\mathrm{m} / \mathrm{s}]}\end{array}\right]$ \\
\hline C35 & 2467 & 44.6 & 47.6 & 4.0 & 0.99 & 1.35 & 119.7 & 0.95 & 2.25 & 118.0 \\
\hline C75 & 2506 & 72.8 & 87.4 & 5.2 & 0.98 & 1.47 & 140.4 & 0.90 & 2.49 & 122.7 \\
\hline C110 & 2570 & 112.5 & 123.6 & 6.2 & 1.00 & 1.33 & 152.6 & 0.89 & 2.67 & 140.3 \\
\hline
\end{tabular}

\section{Component tests}

\subsection{Setup}

Custom-made wooden moulds were used to cast slabs with nominal dimensions $625 \mathrm{~mm} \times$ $625 \mathrm{~mm} \times 50 \mathrm{~mm}$ (see Fig. 2(a) and (b)). 12 slabs were cast for each concrete quality and numbered $\mathrm{C} 35-1$ to $\mathrm{C} 35-12$ (and correspondingly for C75 and C110). Plastic tubes were inserted through 12 equally spaced cut-outs for bolt holes. A reinforcement bar with diameter $8 \mathrm{~mm}$ looping on the outside of the bolt holes was added to provide a lifting point and to restrain shrinkage. Thus, the central part of the slabs to be impacted by projectiles were plain 
concrete. In the test rig, the slabs were fixed with four massive clamps although holes for a bolted connection was available (for subsequent work). While the boundary conditions are important for distributed loads like shock waves [11], they are thought to be of minor importance for ballistic impact if the in-plane distance between individual shots is large enough [12]. Here, only one shot in the centre of the slab is allowed before it is replaced.

The $196 \mathrm{~g}$ projectiles were manufactured from Arne tool steel and heat treated to 53 Rockwell $\mathrm{C}$ after machining (geometry shown in Fig. 2(c)). The ogive-nose projectiles with critical-radius-head 3 were mounted in a sabot and launched by a compressed air gun [10]. Two synchronised Phantom v2511 high-speed cameras filmed the tests. Accurate optical measurements based on the high-speed images gave the initial velocity $v_{\mathrm{i}}$ and the residual velocity $v_{\mathrm{r}}$. This also gives the velocity-time curve of the projectile when it is not obscured.
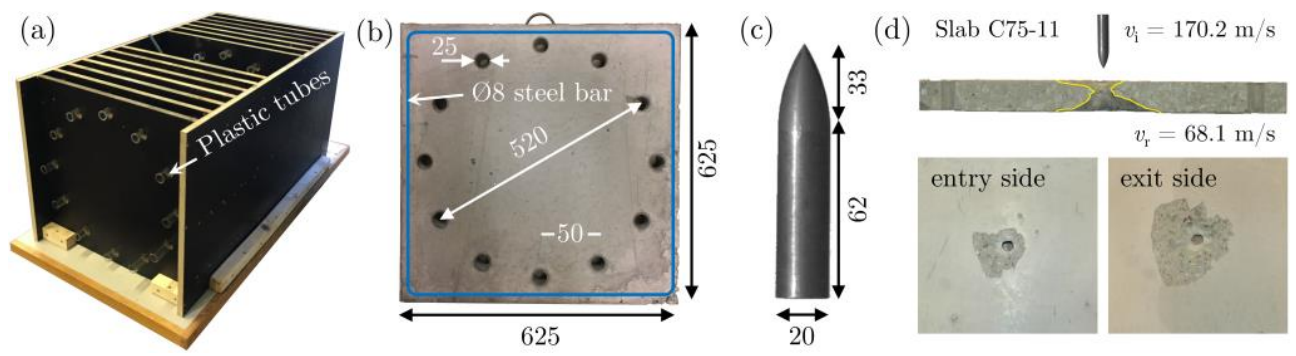

Fig. 2. Component test setup, (a) wooden moulds for casting, (b) geometry of concrete slabs, (c) geometry of ogive-nose projectile, and (d) typical perforation pattern.

\subsection{Results}

A typical perforated slab is shown in Fig. 2(d), exemplified by slab C75-11. The sliced crosssection shows that there is hardly any tunnelling region between the two craters. The tests further show that the spalling craters on the entry side were smaller than the scabbing craters on the exit side. This was consistent for all slabs and all concretes and in line with previous work [2]. The crater sizes and mass loss after impact increased with increasing concrete strength, also observed in [13]. The average mass loss for all tests was $0.5 \mathrm{~kg}, 0.6 \mathrm{~kg}$ and $1.0 \mathrm{~kg}$ for the C35, C75 and C110 concretes, respectively. Higher strength means more brittle in this case, and thus more fragmentation. This result may also be seen in Fig. 3, where the dust cloud and number of debris appear largest for the C110 concrete for roughly equal $v_{\mathrm{i}}$.

Based on the measured $v_{\mathrm{i}}$ and $v_{\mathrm{r}}$, ballistic limit curves were estimated. This was done by least squares fits of the model constants in the generalised Recht-Ipson model [14]

$$
v_{\mathrm{r}}=a\left(v_{\mathrm{i}}^{p}-v_{\mathrm{bl}}^{p}\right)^{1 / p}
$$

where $a$ and $p$ are considered empirical constants. Due to scatter in the experimental data at impact velocities close to the ballistic limit - especially for the $\mathrm{C} 110$ concrete - it was hard to determine the ballistic limit velocities $v_{\mathrm{bl}}$ exactly. Thus, $v_{\mathrm{bl}}$ was taken as the highest impact velocity not giving complete perforation (only scabbing), while $a$ and $p$ were fitted to the experimental data. The results of the least squares fits are given in Table 1 for all three concretes, and the curves are plotted in Fig. 4(a)-(c) along with the experimental data points. A modest linear increase in ballistic limit velocity with increase in compressive strength is observed. Fig. 4(d) shows a plot of the ballistic limit velocity versus cube compressive strength $f_{\text {cc }}$. Here, a tripling of the compressive strength increased the ballistic limit velocity by approximately $27 \%$. One possible reason for this result is that the tensile splitting strength $f_{\mathrm{t}}$ increased by only $55 \%$ from $\mathrm{C} 35$ to $\mathrm{C} 110$. The pitch angle was less than $1.5^{\circ}$ in all tests. 


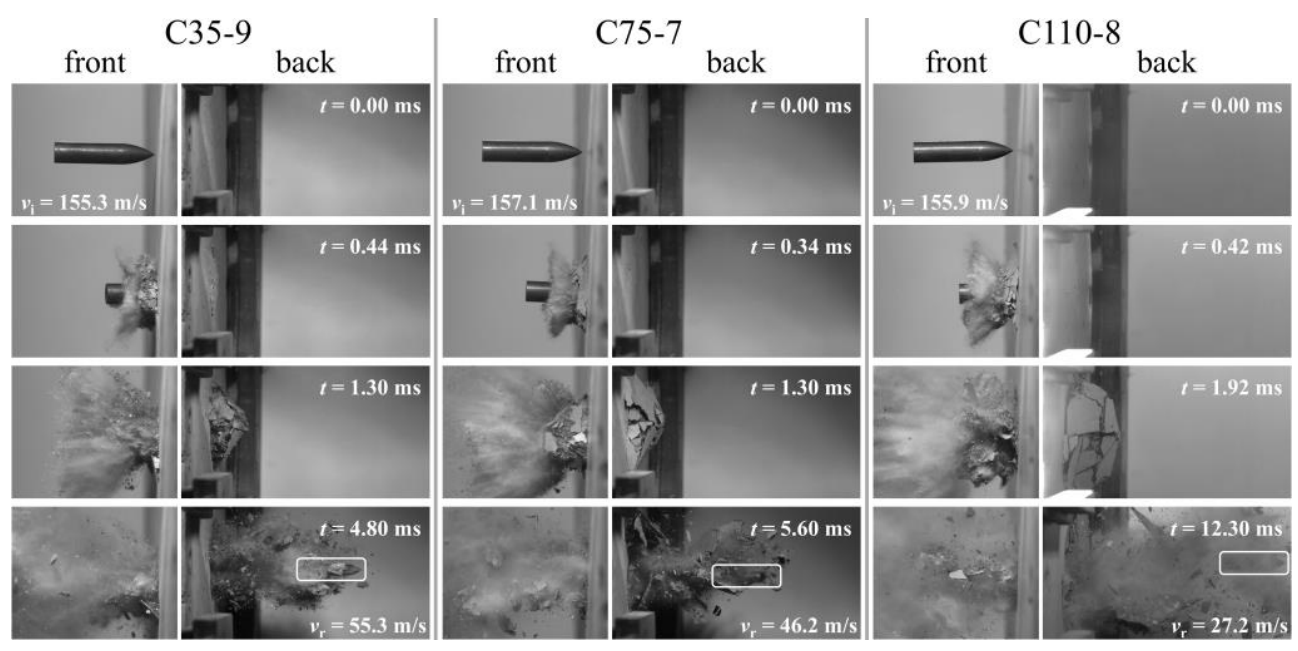

Fig. 3. Time lapse from high-speed camera images of ballistic impact tests for test $\mathrm{C} 35-9$ (left column), C75-7 (centre) and C110-8 (right).
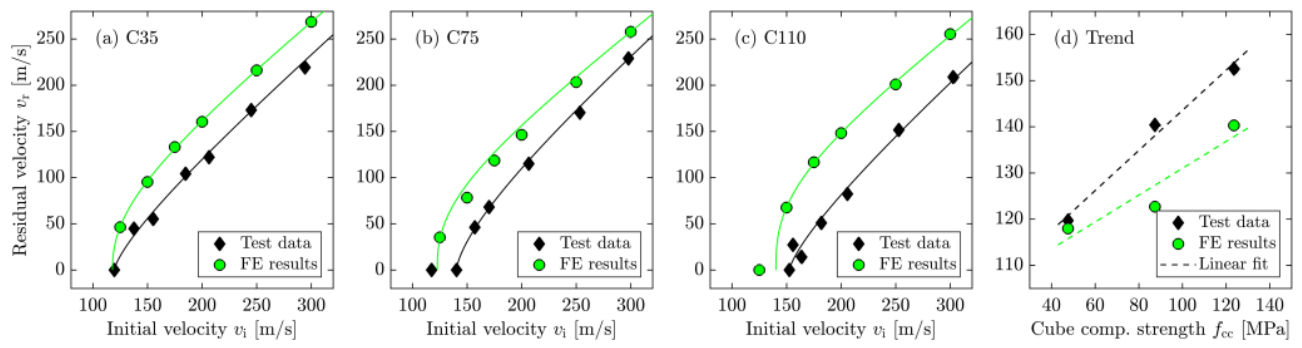

Fig. 4. Experimentally and numerically obtained ballistic limit curves for (a) C35, (b) C75 and (c) C110 concretes, and (d) ballistic limit as function of cube compressive strength.

\section{Numerical simulations}

\subsection{Constitutive relation and calibration}

All numerical simulations presented in this study use the MHJC model to describe the constitutive behaviour of the concretes. A complete description of the model is given in [3].

The cylinder tests in Fig. 1(b) were simulated using an axisymmetric model in the explicit finite element solver LS-DYNA [15]. The model shown in Fig. 5(a) has rigid top and bottom plates and a concrete cylinder with 4-node elements $(50 \times 200$ elements, $1.0 \mathrm{~mm}$ element size, element type 15 , hourglass type 6 ) with $2 \mathrm{D}$ automatic surface-to-surface contact with coefficient of friction of 0.4 . The top plate was given a constant velocity $v_{\mathrm{p}}$ and the force and the engineering strain $e$ were logged exactly as in the experiments. Time scaling with the strain rate sensitivity parameter $C=0$ was used, and the energy ratio remained close to unity for all simulations.

The material constants for density, unconfined compressive strength and tensile strength were taken from Table 1. The reference strain rate was $10^{-5} \mathrm{~s}^{-1}$ based on the material tests, while the crush limit $P_{\text {crush }}$ was assumed equal to $f_{\text {cyl }} / 3$ and the volumetric crushing strain equal to $f_{\text {cyl }} /\left(3 K_{1}\right)$ where $K_{1}$ is the initial bulk modulus. The pressure-volumetric strain constants $K_{1}, K_{2}, K_{3}, P_{\text {lock }}$ and $\mu_{\text {lock }}$ were taken from Ref. [9]. The shear modulus $G$, the pressure hardening constants $B$ and $N$, the damage constants $\alpha$ and $\beta$, and the minimum strain 
to failure $\varepsilon_{\mathrm{fp} \text {,min }}$ were all obtained by inverse modelling of the cylinder compression tests and are given in Table 2. This approach has been successful in previous work [16]. The resulting engineering stress-strain curves match the experiments well and are plotted as dashed lines in Fig. 1(b).
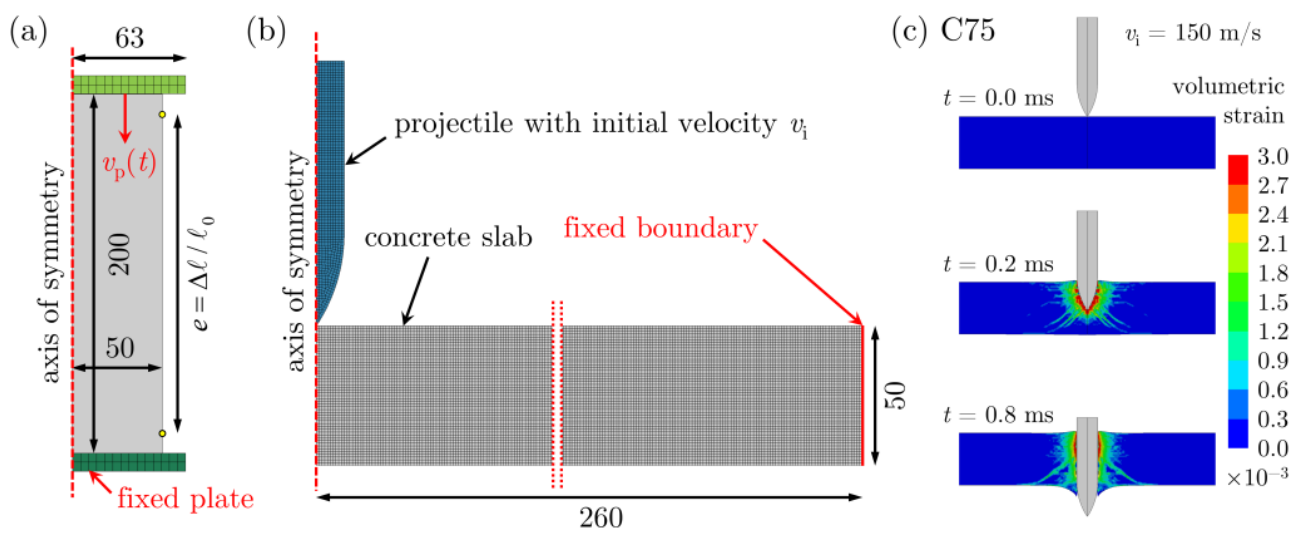

Fig. 5. Setup of 2D axisymmetric finite element simulations for (a) cylinder compression test and (b) ballistic impact tests, and (c) fringe plot of the volumetric strain during impact simulation of a C75 slab.

Table 2. Material constants for MHJC model obtained by inverse modelling.

\begin{tabular}{lllllll}
\hline Concrete & $G[\mathrm{MPa}]$ & $B[-]$ & $N[-]$ & $\alpha[-]$ & $\beta[-]$ & $\varepsilon_{\text {fp,min }}[-]$ \\
\hline C35 & 19118 & 1.366 & 0.349 & 0.942 & 0.344 & 0.017 \\
C75 & 22675 & 1.651 & 0.558 & 0.967 & 0.151 & 0.014 \\
C110 & 27711 & 1.145 & 0.100 & 0.057 & 0.652 & 0.005 \\
\hline
\end{tabular}

\subsection{Setup of impact simulations}

To minimise mesh dependency, the same element type and size was used for the impact simulations in a computational cell approach [17]. The elements were set to erode when the equivalent strain exceeded 1.0 or the time step dropped below $1 / 1000^{\text {th }}$ of the initial value, thus preventing mesh distortion. The concretes were represented by the calibrated MHJC model with $C=0.04$, and the projectile an elastic-plastic model (*MAT_003 in LS-DYNA) with linear isotropic hardening. The projectile had a Young's modulus of $204000 \mathrm{MPa}$, a Poisson ratio of 0.33 , a yield stress of $1900 \mathrm{MPa}$ and a tangent modulus equal to $15000 \mathrm{MPa}$. The setup is sketched in Fig. 5(b).

\subsection{Results}

Results in terms of ballistic limit curves are shown in Fig. 4(a), (b) and (c) for C35, C75 and C110, respectively. The relative differences between the concrete qualities were maintained in the simulation results, and the ballistic limit velocities were determined by a least squares fitting of $a, p$ and $v_{\mathrm{bl}}$ in the Recht-Ipson model. The values are listed in Table 1. The results are as seen reasonably accurate given the rather uncomplicated model. The qualitative results are also satisfying, as illustrated by Fig. 5(c) where the volumetric strain is shown as fringe plots at various instants during the penetration process.

A parametric study was carried out on the $\mathrm{C} 110$ concrete, where $f_{\text {cyl }}$ and $f_{\mathrm{t}}$ were doubled and halved, changing only one parameter at the time. Doubling $f_{\text {cyl }}$ from $112.5 \mathrm{MPa}$ to $225 \mathrm{MPa}$ increased the ballistic limit by a meagre $1.6 \%$, while halving it reduced $v_{\mathrm{bl}}$ by $11.6 \%$ from $140.3 \mathrm{~m} / \mathrm{s}$. The corresponding number for doubling and halving $f_{\mathrm{t}}$ were $20.8 \%$ 
and $21.6 \%$, respectively. This result suggests that the tensile strength is far more influential on the perforation resistance of thin concrete slabs than the compressive strength. The modest increase in the experimental results in Fig. 4(d) support this. Further, omitting strain rate sensitivity in the material by setting $C=0.0$ reduced $v_{\text {bl }}$ by $10.9 \%$, while using $C=0.08$ increased $v_{\text {bl }}$ by $3.4 \%$. Finally, increasing the friction coefficient from 0.0 to 0.4 increased the ballistic limit by $14.0 \%$.

\section{Concluding remarks}

The material test results were in line with expectation for the $\mathrm{C} 35, \mathrm{C} 75$ and $\mathrm{C} 110$ concretes. The DIC measurements enabled reasonable material parameters to be obtained, as illustrated by the experimental and numerical comparison in Fig. 1(b). The ballistic limit of the slabs increased almost linearly with concrete strength, where tripling $f_{\text {cyl }}$ increased $v_{\mathrm{bl}}$ by only $27 \%$. For these thin slabs, the tensile strength appears to be the most dominant material parameter. This was also suggested by the finite element simulations, where $f_{\mathrm{t}}$ was found to be the by far most influential of the parameters studied. In general, the simulations gave good conservative results. The MHJC model is easy to calibrate and implement, and it provides a good and reliable alternative to more advanced concrete models for which accurate material parameter sets may be difficult to obtain.

The work was been carried out with financial support from the Norwegian Defence Estates Agency and the Centre of Advanced Structural Analysis (CASA), Centre for Research-based Innovation, at the Norwegian University of Science and Technology and the Research Council of Norway through project no. 237885 (CASA). The authors would also like to acknowledge Mr. Steinar Seehuus, Mr. Trond Auestad, Ms. Guri Lillehaug and Ms. Marte Vestermo Nesje for assistance with the various experimental programmes.

\section{References}

[1] M.J. Forrestal, D.J. Frew, S.J. Hanchak, N.S. Brar, Int. J. Imp. Eng. 18, p. 465-476 (1996)

[2] RP. Kennedy, Nucl. Eng. Des. 37, p. 183-203 (1976)

[3] M. Polanco-Loria, O.S. Hopperstad, T. Børvik, T. Berstad, Int. J. Imp. Eng. 35, p. 290303 (2008)

[4] S.J. Hanchak, M.J. Forrestal, E.R. Young, J.Q. Ehrgott, Int. J. Imp. Eng. 12, p. 1-7 (1992)

[5] T. Børvik, O.E. Gjørv, M. Langseth, Conc. Int. 29, p. 45-50 (2007)

[6] J.D. Riera, Nucl. Eng. Des. 115, p. 121-131 (1989)

[7] L.Y. Xu, H. Xu, H.M. Wen, Int. J. Imp. Eng. 125, p. 39-55 (2019)

[8] V.R. Feldgun, D.Z. Yankelevsky, Int. J. Prot. Struct. 11, p. 159-184 (2019)

[9] T.J. Holmquist, G.R. Johnson, W. Cook, A computational constitutive model for concrete subjected to large strains, high strain rates, and high pressures, in Proceedings of the $14^{\text {th }}$ International Symposium on Ballistics, Quebec City, Canada (1993)

[10]T. Børvik, M. Langseth, O.S. Hopperstad, K.A. Malo, Int. J. Imp. Eng. 22, p. 855-886 (1999)

[11]M. Kristoffersen, J.E. Pettersen, V. Aune, T. Børvik, Eng. Struct. 174, p. 242-255 (2018)

[12]T. Børvik, S. Dey, A.H. Clausen, Int. J. Imp. Eng. 36, p. 948-964 (2009)

[13]A.N. Dancygier, D.Z. Yankelevsky, Int. J. Imp. Eng. 18, p. 583-599 (1996)

[14]R.F. Recht, T.W. Ipson, J. Appl. Mech. 30, p. 384-390 (1963)

[15]Livermore Software Technology (LST), An Ansys Company. LS-Dyna Keyword User's Manual, LS-DYNA R12 (2020)

[16]M. Kristoffersen, A. Minoretti, T. Børvik, Eng. Struct. 233 (2021) 111543

[17]C. Ruggieri, T.L. Panontin, R.H. Dodds, Int. J. Fract. 82, p. 67-95 (1996) 